\title{
ГЕОЭКОЛОГИЯ
}

\section{Консорциум неспорообразующих микроорганизмов как средство для рекультивации почв}

\author{
В. В. Вершинин ${ }^{1}$, В. М. Ретивов ${ }^{2}$, А. С. Нартов ${ }^{1,2}$ 凶 \\ ${ }^{1}$ Государственный университет по землеустройству, Российская Федерация \\ (105064, г. Москва, ул. Казакова, 15) \\ ${ }^{2}$ НИЦ «Курчатовский институт - ИРЕА», Российская Федераџия \\ (107076, г. Москва, ул. Богородский Вал, 3)
}

\begin{abstract}
Аннотация: Цель исследования - изучение возможности применения микробиологического препарата, изначально разработанного для переработки нефтепродуктов, в качестве средства, утилизирующего полициклические ароматические углеводороды (ПАУ) в техногенно-загрязнённых почвах промышленно-урбанизированных территорий.

Meтоды. В ходе проведённых исследований проанализированы известные способы деструкции ПАУ и наиболее распространённые способы рекультивации, применяемые в настоящее время. Показано, что задача улучшения качества загрязнённых почв может быть решена с помощью препарата, содержащего неспорообразующие микроорганизмы родов Candida, Pseudomonas и Rhodococcus, разработанного в ООО «НПО Биотехсоюз» и ранее не использовавшегося для утилизации ПАУ. Эффективность данного препарата продемонстрирована на примере 64 образцов почвы, отобранных по 4 направлениям в радиусе 5 км от двух промышленных предприятий города Москвы и Московской области (мусоросжигательный завод № 3 и НПО «Луч», город Подольск, производящий металлические изделия, соответственно).

Результаты представлены в виде пространственных схем, демонстрирующих текущие уровни загрязнения почв (не обработанных препаратом) и ожидаемые уровни загрязнения (после обработки). Зонирование исследованных территорий основано на использовании ранее предложенного одним из авторов статьи индекса общего токсического воздействия биологически доступных полициклических ароматических углеводородов, который учитывает не только концентрации отдельных загрязнителей в почве, но также степень их воздействия на живые организмы.

Выводы. Выявлены некоторые общие закономерности и особенности переработки ПАУ микроорганизмами, относящимися к вышеперечисленным родам. Показано, что степень переработки этих соединений зависит от их молекулярного строения.
\end{abstract}

Ключевые слова: полициклические ароматические углеводороды (ПАУ), техногенное загрязнения почвы, рекультивация почвы, микробиологическая деструкция ПАУ.

Для цитирования: Вершинин В. В., Ретивов В. М., Нартов А. С. Консорциум неспорообразующих микроорганизмов как средство для рекультивации почв // Вестник Воронежского государственного университета. Серия: География. Геоэкология, 2021, № 1, с. 57-64. DOI: https://doi.org/10.17308/ geo.2021.1/3256

\section{ВВЕДЕНИЕ}

Одной из актуальных проблем современной экологии, медицины и почвоведения является возможность интенсификации процесса распада полиароматических углеводородов (ПАУ) в за- грязнённых почвах. Это объясняется, во-первых, значительной эмиссией соединений этой группы автомобильным транспортом и промышленными предприятиями, а, во-вторых, их негативным (канцерогенным, мутагенным и тератогенным) воздействием на живые организмы и на челове-

(C) Вершинин В. В., Ретивов В. М., Нартов А. С., 2021

$\triangle$ Нартов Александр Сергеевич, e-mail: nartovalexander@gmail.com 
ка, в частности. В силу своих физико-химических свойств полиароматические углеводороды хорошо адсорбируются почвой и практически не подвергаются деструкции в естественных условиях, что приводит к их постепенному накоплению и, как следствие, ухудшению экологической обстановки, особенно на промышленно-урбанизированных территориях [7]. С другой стороны, вышеперечисленные свойства ПАУ позволяют использовать значение их концентраций в почвах в качестве универсальных индикаторов экологического состояния регионов с развитой промышленной, транспортной и иной инфраструктурой, а также с высокой плотностью населения. Авторами этой статьи ранее была разработана система зонирования территорий, подвергающихся воздействию техногенных полиароматических углеводородов, в основе которой лежит принцип качественных изменений, наблюдаемых в окружающей среде при переходе от уровня к уровню. Количественным показателем, отражающим эти изменения, является индекс общего токсического воздействия биологически доступных ПАУ (I), который численно равен такой концентрации бенз(а)пирена, токсическое воздействие которой эквивалентно воздействию суммы полиароматических углеводородов, обнаруженных в почве. Помимо концентраций загрязняющих веществ класса ПАУ данный показатель учитывает различие в биологическом воздействии каждого отдельного компонента, выражающиеся в факторах токсичной эквивалентности и константе биологической доступности. В ходе апробации разработанной системы зонирования на территориях, прилегающих к промышленным предприятиям Москвы и Московской области, были выявлены зоны с высоким содержанием токсичных и биологически доступных полиароматических углеводородов [2]. Это актуализирует необходимость проведения мероприятий по рекультивации таких загрязнённых земель.

Полиароматические углеводороды проявляют низкую химическую активность. Но некоторые представители данной группы могут испытывать превращения под воздействием УФ-излучения, окисляясь до менее токсичных соединений (в атмосфере - также, вступая по радикальному механизму в химические реакции с различными фотоокисдантами, например, озоном). В поверхностных слоях почвы полиароматические углеводороды претерпевают изменения под воздействием солнечного света, однако основным механиз- мом их деградации в этом случае выступает уже микробиологическая деструкция.

Но в естественных условиях этот процесс идёт крайне медленно. Так, по данным, приведённым в обзоре А.Б. Бигалиева и его коллег, даже при загрязнении бенз(а)пиреном на уровне, не превышающем установленный ПДК, без внешнего вмешательства почва восстанавливается не менее 10 лет, поскольку для естественной микрофлоры почвы полиароматические углеводороды относятся к ксенобиотикам и не могут быть использованы ими в качестве привычного источника питания. Очевидно, что в условиях развитой транспортной и промышленной инфраструктуры эмиссия полиароматических углеводородов во много раз превышает скорость их деградации в почве. Это приводит к аккумуляции значительных концентраций данных соединений в городских почвах, снижая качество окружающей среды и ухудшая санитарно-гигиенические условия.

Дополнительное (кроме солнечного света) воздействие УФ-излучением на загрязнённые почвы с целью распада адсорбированных на их поверхности ПАУ не представляется возможным как технически, так и с точки зрения экологии, поскольку негативно скажется на состоянии почвенных организмов. Стоит отметить, что этот метод широко применяется для очистки питьевой и промышленной воды, где не требуется сохранения её микрофлоры.

Воздействие на загрязнители группы ПАУ химическими окислителями проще реализовать технически, но в силу стойкости данных соединений для этого требуется применение сильных окислителей. Такие вещества, как правило, сами относятся к числу крайне токсичных, едких (например, акролеин) или даже взрывоопасных (большинство органических пероксидов). Кроме того, все они не являются селективными окислителями по отношению к полиароматическим соединениям, то есть, приводят к деструкции практически любого органического вещества, в том числе и биологических тканей. Не исключается и относительно безопасный перманганат калия. К тому же известно, что процесс окисления перманганатом катализируется в присутствии минеральных кислот (наиболее часто используется серная кислота). При этом в результате реакции образуются различные соединения марганца (в основном в степени окисления +2 ) [3], относящегося к числу тяжёлых металлов, и накопление которого в почвах выше определённого уровня 
приводит к нарушениям процесса образования хлорофилла в листьях растений, образованию на них некротических пятен, накоплению оксида марганца (IV) в клетках эпидермиса и другим негативным последствиям. Отрицательное воздействие марганца на человека заключается в нарушении функций различных систем - ЦНС, почек, кроветворной, костной, пищеварительной систем, иммунных и антиоксидантных процессов [5].

Таким образом, наиболее приемлемым способом утилизации полиароматических углеводородов в почвах нам представляется их микробиологическая деструкция. Данное направление исследований является довольно молодым - так, ещё менее тридцати лет назад практически не были известны микроорганизмы, способные приводить к значительной деструкции полиароматических углеводородов, имеющих в структуре более трёх колец [8]. Но в последние годы появились публикации, где описаны микробиологические препараты, воздействие которых на загрязнённые почвы заметно снижает концентрацию тяжёлых ПАУ, в том числе, бенз(а)пирена - наиболее канцерогенного из них $[4,9]$. Механизм, по которому в этом случае происходит деградация конденсированных углеводородов, в целом можно объяснить способностью микроорганизмов окислять эти соединения с последующим разрушением ароматической структуры, хотя конкретные метаболические цепочки различны для разных соединений и микроорганизмов. В ходе перечисленных процессов полиароматические углеводороды превращаются в более реакционноспособные и значительно менее токсичные вещества [1]. Но, несмотря на проводимые в настоящее время исследования в данной области, вопрос микробиологической деструкции полиароматических углеводородов остаётся малоизученным, а рекультивация почв, основанная на осуществлении этого процесса, практически не применяется на практике.

\section{МЕТОДИКА ЭКСПЕРИМЕНТА}

В ходе проведённых нами исследований были изучены возможности рекультивации почв, загрязнённых полиароматическими углеводородами техногенного происхождения с помощью комплексного биопрепарата, разработанного ООО «НПО Биотехсоюз». Препарат представляет собой консорциум неспорообразующих микроорганизмов родов Candida, Pseudomonas, Rhodococcus, вылеленных из техногенно-загрязнённых почв. Изначально препарат разрабатывался с иелью деструкичи нефтепродуктов. Однако, поскольку нефтеперерабатывающие микроорганизмы используют в качестве источника энергии углерод, было выдвинуто предположение, что полиароматические углеводороды также могут служить для них источником питания, причём, не исключено, что более энергетически ёмким, так как в ароматических молекулах доля углерода выше, чем в молекулах алифатических углеводородов.

Образцы почвы отбиралив вадиусе 5 кмот двух стациионарных источников эмиссии техногенных ПАУ - НПО «Луч» (2. Подольск, Московская область) и мусоросжигательный завод № 3 (г. Москва). Отбор производился по четырём направлениям на расстояниях 0,$2 ; 0,5 ; 1 ; 1,5 ; 2 ; 3 ; 4$ и 5 км от источников (по 32 точкам для каждого объекта). Отобранные образиьл усредняли, сушили до постоянной массы, после чего проводили экстракцчию полиароматических углеводородов ацетонирилом (30 г образца, двукратная экстракция 50 мл ацетонирила). Полученные экстракты упаривали, разбавляли 1 мл ацетонитрила и определяли концентрацию 12 аренов, имеюших в структуре конденсированные бензольные кольияа (от 2 до 5) методом газовой хроматографии-масс-спектрометрии [6].

Параллельно 30 г каждого образияа обрабатьвали 1\%-ным раствором биопрепарата в течение 100 часов, после чего проводили экстракиию и определение концентрации тех же 12 соединений по описанной выне схеме.

Кроме того, с иелью определения содержания гумусовых кислот, в каждом образие было определено содержание общего органического углерода путём прокаливания 10 г образца в муфельной печи при температуре $525^{\circ} \mathrm{C}$ в течение 4 часов.

Поскольку различные ПАУ оказывают разное воздействие на живые организмы, их общее содержание в образцах - малоинформативный показатель. Поэтому для выделения уровней токсического воздействия полиароматических углеводородов в данной работе использовались значения соответствующего индекса $\boldsymbol{I}$. Такой способ зонирования позволяет учесть не только концентрации ПАУ в почвах, но и токсичность каждого из них, а также степень их связывания гумусовыми кислотами почвы (биодоступность) [2]. По результатам проведённых исследований были построены схемы распределения полиароматических углеводородов с учётом рельефа местности. Для построения схем использовалось ПО Surfer 9, метод Kriging. 


\section{ОБСУЖДЕНИЕ РЕЗУЛЬТАТОВ}

В результате обработки образцов почвы биопрепаратом при указанных выше условиях наблюдалось снижение суммарной концентрации полиароматических углеводородов в 1,7-2,2 раза. Изменение уровня токсического воздействия биологически

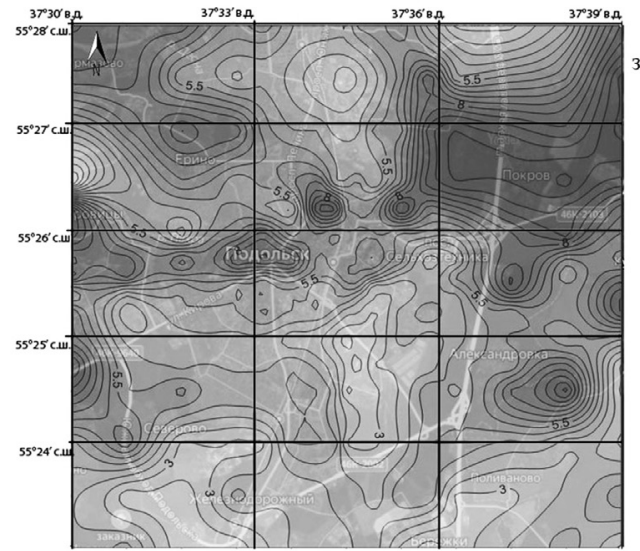

A

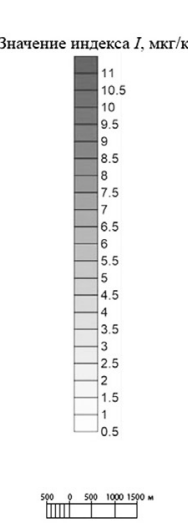

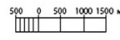

Puc. 1. Схема распределения территорий в радиусе 5 км от НПО «Луч» (г. Подольск) по уровням общего токсического воздействия биодоступных ПАУ: (А) - до и (В) - после обработки биопрепаратом

[Fig. 1. Distribution scheme of territories within a radius of $5 \mathrm{~km}$ from NPO «Luch» (Podolsk City) according to the levels of the general toxic effect of bioavailable PAHs: (A) - before and (B) - after treatment with a biological product]

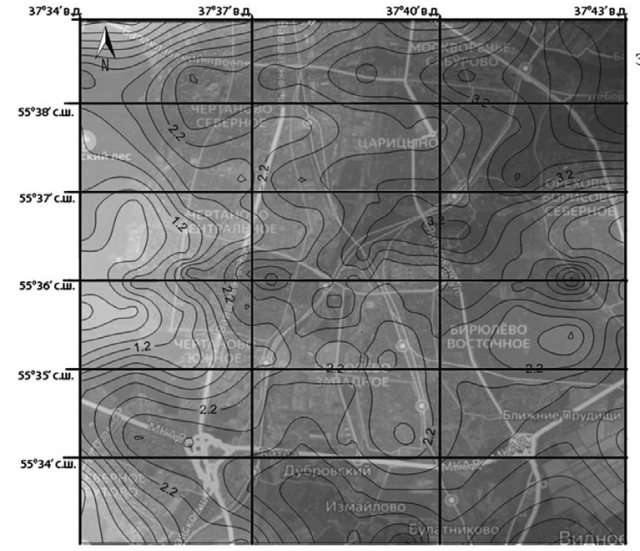

A
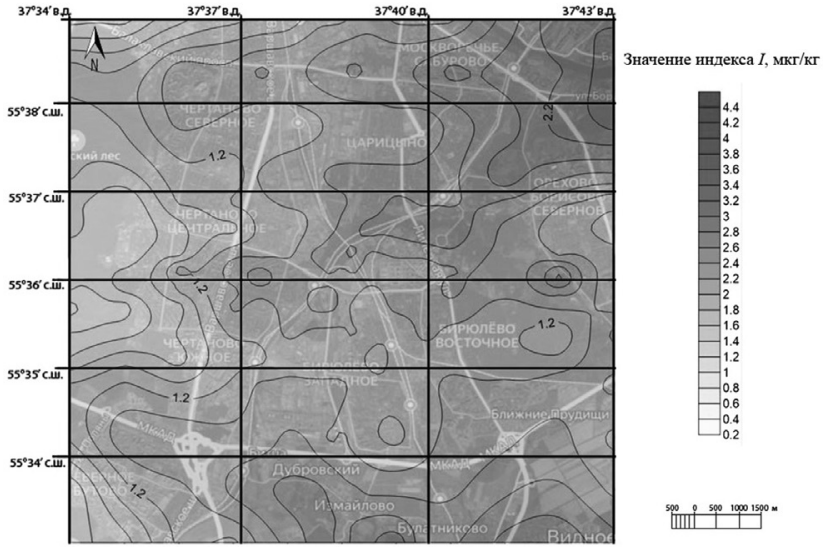

$\mathrm{B}$

Puc. 2. Схема распределения территорий в радиусе 5 км от мусоросжигательного завода №3 (г. Москва) по уровням общего токсического воздействия биодоступных ПАУ: (А) - до и (В) - после обработки биопрепаратом

[Fig.2. Distribution scheme of territories within a radius of $5 \mathrm{~km}$ from the incineration plant No. 3 (Moscow) according to the levels of the general toxic effect of bioavailable PAHs: (A) - before and (B) - after treatment with a biological product]

Использование значений индексов $\boldsymbol{I}$ позволяет выделить 7 качественных уровней токсического воздействия, первый из которых означает полное отсутствие аналитических сигналов, соответствующих полиароматическим углеводородам, а седьмой - превышению максимального показателя (соответствующего такому суммарному токсическому эффекту 12 ПАУ, который создавал бы только бенз(а)пирен при концентрации, равной ПДК) как для лёгких (2-3 ароматических кольца), так и для тяжёлых (4-5 ароматических колец) аренов.

По результатам проведённых исследований, наиболее интенсивно процесс утилизации полиароматических углеводородов проходит при высоких уровнях загрязнения за 100 часов, снижаясь с шестого уровня (превышение максимального показателя только для тяжёлых ПАУ) до третьего или четвёртого (оба показателя ниже максималь- 
ного, но в одних точках преобладают лёгкие ПАУ (3 уровень), а в других - тяжёлые (4 уровень)). Единственная область, отнесённая к седьмому уровню загрязнения (фиолетовая область) на юге (рис. 2), была очищена после биообработки до шестого уровня (то есть, общий токсический эффект тяжёлых ПАУ по-прежнему остался выше нормы, а токсический эффект лёгких ПАУ перешёл отметку ниже максимального).
Вероятно, степень утилизации конкретного соединения класса аренов зависит от строения их молекулы. Так, было замечено, что лучше всего подвергаются переработке консорциумом микроорганизмов четырёхчленные полиароматические углеводороды (примерно на 30-50 \% интенсивнее, чем 3- и 5-членные), отнесённые к тяжёлым ПАУ, что объясняет наблюдаемые изменения (рис. 3).

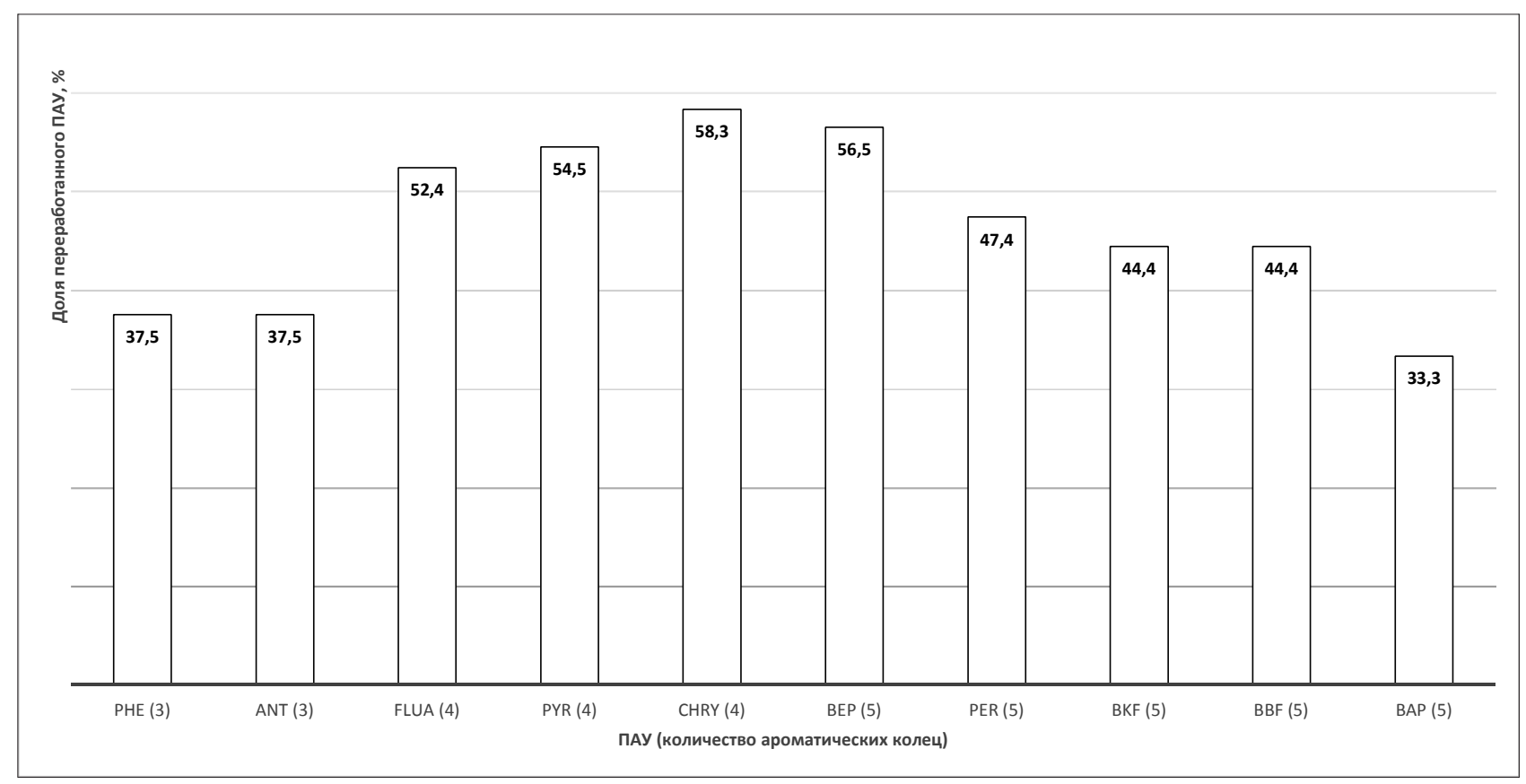

Puс. 3. Зависимость доли переработанного ПАУ от числа ароматических колец в его молекуле

[Fig. 3. Dependence of the fraction of processed PAHs on the number of aromatic rings in its molecule]

Кроме того, стоит отметить, что способ конденсации ароматических колец в молекуле также, судя по всему, влияет на возможность микробиологической утилизации ароматического соединения. Ангулярные и линейные ПАУ в большей степени подвергаются переработке микроорганизмами, нежели углеводороды с кластерным строением (в среднем на $10 \%$ интенсивнее для 4-членных и на $20 \%$ - для 5-членных). Исключение составил только 5-членный бенз(а)пирен, уменьшение концентрации которого оказалось сопоставимо с уменьшением концентрации 4-членных ПАУ. Ангулярные и линейные структуры с одинаковым количеством ароматических колец перерабатываются практически в равной степени (например, снижение концентрации антрацена и фенантрена в большинстве образцов находилось в диапазоне 35-40 \%).

\section{ЗАКЛЮЧЕНИЕ}

Проведённые исследования показали, что биопрепарат, представляющий собой консорциум неспорообразующих углеводородокисля- ющих микроорганизмов Candida, Pseudomonas u Rhodococcus, может быть использован не только для деструкиии отходов нефтяной промышленности, но и в качестве средства для снижения кониенттации таких стойких органических загрязнителей в почвах городских территорий, как полиароматические углеводороды, включая наиболее каниерогенный из них - бенз(а)пирен. Проведение регулярного мониторинга $u$ зонирования техногенно-загрязнённых территорий с учётом биологического воздействия этих экотоксикантов в совокупности с выявленными закономерностями проиесса биологической деструкиии ПАУ позволят определить те площади, которые должсны быть подвергнуты рекультивачии в первую очередь. Также полученные данные могут быть использованы для расчёта ориентировочной длительности прочесса снижения кониентрации полиароматических углеводородов в загрязнённых почвах до более низкого уровня. 
Кроме того, стоит заметить, что, согласно Постановлению Правительства РФ от 13.09.2016 № 913 «O ставках платы за негативное воздействие на окружаюшую среду и дополнительных коэффичиентах», ставка плать за выброс в атмосферу единицы массы бенз(а) пирена является одной из самых высоких (вторая по величине после ставки за выброс диоксинов). Поэтому применение данного биопрепарата в некоторых случаях может оказаться гораздо более выгодным, нежели осуществление таких выплат.

\section{СПИСОК ЛИТЕРАТУРЫ}

1. Брянская А.В., Уварова Ю.Е., Слынько Н.М., Демидов Е.А., Розанов А.С., Пельтек С.Е. Теоретические и практические аспекты проблемы биологического окисления углеводородов микроорганизмами // Вавиловский журнал генетики и селекции, 2014, т. 18, № 4/2, с. 999-1012.

2. Вершинин В.В., Ретивов В.М., Нартов А.С., Холин Р.Н. Экологический мониторинг промышленно-урбанизированных территорий с использованием новой системы их зонирования // Землеустройство, кадастр и мониторинг земель, 2020, № 2, с. 70-75.

3. Гуров А.Ф. Трудные случаи составления OX-RED-реакций // Альманах современной науки и образования, 2009, № 5, с. 39-45.

4. Егорова А. В., Мамонтова В.Н., Афти И. А., Никифоров В.А., Янкевич М.И., Жаковская 3. А. Бакте- риальная деградация полициклических ароматических углеводородов в почвах // Известия СПбГТИ (ТУ), 2014, № 23, с. 75-78.

5. Мазунина Д. Л. Негативные эффекты марганца при хроническом поступлении в организм с питьевой водой // Экология человека, 2015, № 3, с. 25-31.

6. Филимонов В. Д., Слепченко Г.Б., Белянин М. Л., Нартов А.С. Определение полициклических ароматических углеводородов в почвах с использованием газовой хроматографии - масс-спектрометрии // Аналитика и контроль, 2015, т. 19, № 4, с. 310-315.

7. Abdel-Shafy H.I., Mansour M.S.M. A review on polycyclic aromatic hydrocarbons: Source, environmental impact, effect on human health and remediation // Egyptian Journal of Petroleum, 2016, no. 25, pp. 107-123. DOI: http://doi.org/10.1016/j.ejpe.2015.03.011

8. Cerniglia C. E. Biodegradation of polycyclic aromatic hydrocarbons // Current Opinion in Biotechnology, 1993, vol. 4, pp. 331-338.

9. Zhu F., Storey S., Ashaari M. M., Clipson N., Doyle E. Benzo(a)pyrene degradation and microbial community responses in composted soil // Environmental Science and Pollution Research, 2017, no. 24 (6), pp. 5404-5414. DOI: http://doi.org/10.1007/s11356-016-8251-3

Конфликт интересов: Авторы декларируют отсутствие явных и потенциальных конфликтов интересов, связанных с публикацией настоящей статьи.

Поступила в редакиию 02.09.2020 Принята к публикащии 02.03.2021 


\title{
GEOECOLOGY
}

UDC 504.064.47

ISSN 1609-0683

DOI: https://doi.org/10.17308/geo.2021.1/3256

\section{Consortium of Non-Spore-Forming Microorganisms as a Means for Reclamation of Soils}

\author{
V. V. Vershinin ${ }^{1}$, V. M. Retivov ${ }^{2}$, A. S. Nartov ${ }^{1,2} \bowtie$ \\ ${ }^{1}$ State University of Land Management, Russian Federation \\ (15, Kazakova st., Moscow, 105064) \\ ${ }^{2} S R C$ «Kurchatov Institute - IREA», Russian Federation \\ (3, Bogorodsky Val st., Moscow, 107076)
}

\begin{abstract}
The purpose is to study the possibility of using a microbiological preparation, originally developed for the processing of petroleum products, as a means of utilizing polycyclic aromatic hydrocarbons (PAHs) in technogenically polluted soils of industrial and urbanized areas.

Methods. The known methods of destruction of PAHs and the most common methods of reclamation used at the present time have been analyzed. It is shown that the issue of improving the quality of contaminated soils can be solved with the help of a preparation containing non-spore-forming microorganisms of the genera Candida, Pseudomonas and Rhodococcus, developed by LLC «RPA Biotekhsoyuz» and was not previously used for PAHs utilization. The effectiveness of this preparation was demonstrated on the example of 64 soil samples taken in 4 directions within a radius of $5 \mathrm{~km}$ from two industrial enterprises in Moscow City and the Moscow region (incineration plant No. 3 and RPA «Luch», Podolsk City, which produces metal products, respectively).

Results. Concentrations of PAHs were lower by 1,5-2,4 times for samples treated with the preparation compared to untreated samples. The results are demonstrated on spatial schemes. Schemes are built using the zoning system, which was previously proposed by one of the authors of the article. This zoning system takes into account not only the total concentration of PAHs in the soil, but also the biological effects of each component on living organisms.

Conclusion. The effectiveness of the use of a microbiological preparation for the utilization of PAHs in soil has been shown. It was found that the degree of processing of one or another compound of the PAHs class depends on the structure of their molecule, and also some other regularities were identified.
\end{abstract}

Key words: polycyclic aromatic hydrocarbons (PAHs), technogenic soil pollution, soil reclamation, microbiological destruction of PAHs.

For citation: Vershinin V.V., Retivov V.M., Nartov A. S. Consortium of Non-Spore-Forming Microorganisms as a Means for Reclamation of Soils. Vestnik Voronezskogo gosudarstvennogo universiteta. Seria: Geografia. Geoekologia, 2021, no. 1, pp. 57-64. (In Russ.) DOI: https://doi.org/10.17308/geo.2021.1/3256

\section{REFERENCES}

1. Bryanskaya A.V., Uvarova Yu.E., Slyn'ko N.M., Demidov E.A., Rozanov A.S., Pel'tek S.E. Teoreticheskie i prakticheskie aspekty problem biologicheskogo okisleniya uglevodorodov mikroorganizmami [Theoretical and practical aspects of the problem of biological oxidation of hydrocarbons by microorganisms]. Vavilovskiy zhurnal genetiki i selektsii, 2014, vol. 18, no. 4/2, pp. 999-1012. (In Russ.)

2. Vershinin V.V., Retivov V.M., Nartov A.S., Kholin R.N. Ekologicheskiy monitoring promyshlenno-urbanizirovannykh territoriy $\mathrm{s}$ ispol'zovaniem novoy sistemy ikh zonirovaniya [Environmental monitoring of industrial-urbanized areas using a new zoning system]. Zemleustroystvo, kadastr i monitoring zemel', 2020, no. 2, pp. 70-75. (In Russ.)

3. Gurov A. F. Trudnye sluchai sostavleniya OX-REDreaktsiy [Difficult cases of compiling OX-RED reactions]. Al'manakh sovremennoy nauki i obrazovaniya, 2009, no. 5, pp. 39-45. (In Russ.)

4. Egorova A.V., Mamontova V.N., Afti I.A., Nikiforov V.A., Yankevich M.I., Zhakovskaya Z.A. Bakterial'naya degradatsiya politsiklicheskikh aromaticheskikh

(C) Vershinin V.V., Retivov V. M., Nartov A.S., 2021

$\triangle$ Alexander S. Nartov, e-mail: nartovalexander@gmail.com 
uglevodorodov v pochvakh [Bacterial degradation of polycyclic aromatic hydrocarbons in soils]. Izvestiya SPbGTI (TU), 2014, no. 23, pp. 75-78. (In Russ.)

5. Mazunina D.L. Negativnye effekty margantsa pri khronicheskom postuplenii $\mathrm{v}$ organizm s pit'evoy vodoy [The negative effects of manganese in chronic intake with drinking water]. Ekologiya cheloveka, 2015, no. 3, pp.2531. (In Russ.)

6. Filimonov V.D., Slepchenko G. B., Belyanin M.L., Nartov A.S. Opredelenie politsiklicheskikh aromaticheskikh uglevodorodov v pochvakh s ispol'zovaniem gazovoy khromatografii - mass-spektrometrii [Determination of polycyclic aromatic hydrocarbons in soils using gas chromatography - mass spectrometry]. Analitika i kontrol', 2015, vol.19, no. 4, pp. 310-315. (In Russ.)

7. Abdel-Shafy H.I., Mansour M.S.M. A review on polycyclic aromatic hydrocarbons: Source, environmental

\section{Вершинин Валентин Валентинович}

доктор экономических наук, профессор, заведующий кафедрой почвоведения, экологии и природопользования государственного университета по землеустройству, г. Москва, Российская Федерация, ORCID: 00000001-9046-827X, e-mail: v.vershinin.v@mail.ru

Ретивов Василий Михайлович

кандидат химических наук, и.о. директора НИЦ «Курчатовский институт - ИРЕА, г. Москва, Российская Федерация, ORCID: 0000-0002-3649-2778, e-mail: vasilii retivov@mail.ru

Нартов Александр Сергеевич

заместитель заведующего Аналитическим испытательным центром, научный сотрудник НИЦ «Курчатовский институт - ИРЕА», аспирант государственного университета по землеустройству, г. Москва, Российская Федерация, ORCID: 0000-0002-4280-9639, e-mail: nartovalexander@gmail.ru impact, effect on human health and remediation. Egyptian Journal of Petroleum, 2016, no. 25, pp. 107-123. DOI: http://doi.org/10.1016/j.ejpe.2015.03.011

8. Cerniglia C.E. Biodegradation of polycyclic aromatic hydrocarbons. Current Opinion in Biotechnology, 1993, vol. 4, pp. 331-338.

9. Zhu F., Storey S., Ashaari M.M., Clipson N., Doyle E. Benzo(a)pyrene degradation and microbial community responses in composted soil. Environmental Science and Pollution Research, 2017, no. 24 (6), pp. 54045414. DOI: http://doi.org/10.1007/s11356-016-8251-3

Conflict of interests: The authors declare no information of obvious and potential conflicts of interest related to the publication of this article.

Received 02.09.2020

Accepted 02.03.2021

\section{Valentin V. Vershinin}

Dr. Sci. (Econ.), Professor, Head of the Department of Soil Science, Ecology and Nature Management, State University of Land Management, Moscow, Russian Federation, ORCID: 0000-0001-9046-827X, e-mail: v.vershinin.v@mail.ru

Vasiliy M. Retivov

Cand. Sci. (Chem.), Acting Director of National Research Centre «Kurchatov Institute», Moscow, Russian Federation, ORCID: 0000-0002-3649-2778, e-mail: vasilii_retivov@mail.ru

Alexander S. Narrow

Deputy Head of the Analytical Testing Centre, Researcher of the Institute for Chemical Reagents and High Purity Chemical Substances of National Research Centre «Kurchatov Institute», Postgraduate of the State University of Land Use Planning, Moscow, Russian Federation, ORCID: 0000-0002-4280-9639, e-mail: nartovalexander@gmail.ru 